\title{
Microstructural Evolution of a Low-Carbon Steel during Application of Quenching and Partitioning Heat Treatments after Partial Austenitization
}

\begin{abstract}
M.J. SANTOFIMIA, L. ZHAO, and J. SIETSMA
The "quenching and partitioning" (Q\&P) process has been studied in a low-carbon steel containing $1.1 \mathrm{wt}$ pct aluminum by heat treatments consisting of partial austenitization at $900{ }^{\circ} \mathrm{C}$ and subsequent rapid cooling to a quenching temperature in the range between $125^{\circ} \mathrm{C}$ and $175^{\circ} \mathrm{C}$, followed by an isothermal treatment (partitioning step) at $250{ }^{\circ} \mathrm{C}$ and $350{ }^{\circ} \mathrm{C}$ for different times. Characterization by means of optical and scanning electron microscopy, electron backscattered diffraction (EBSD), magnetization measurements, and X-ray diffraction (XRD) has shown a multiphase microstructure formed by intercritical ferrite, epitaxial ferrite, retained austenite, bainite, and martensite after different stages of tempering. A considerable amount of retained austenite has been obtained in the specimens partitioned at $350{ }^{\circ} \mathrm{C}$ for 100 seconds. Experimental results have been interpreted based on concepts of the martensite tempering, bainite transformation, and kinetics calculations of the carbon partitioning from martensite to austenite.
\end{abstract}

DOI: $10.1007 / \mathrm{s} 11661-008-9701-4$

(C) The Minerals, Metals \& Materials Society and ASM International 2008

\section{INTRODUCTION}

TRANSFORMATION-INDUCED-PLASTICITY (TRIP) steels are usually produced via a thermomechanical process of intercritical annealing followed by rapid cooling to a bainitic transformation regime, to obtain a microstructure of ferrite, bainite, and retained austenite. During the bainitic transformation, the formation of carbides is suppressed, due to the effect of alloying elements such as silicon and aluminum; the austenite is thus enriched with carbon and retained at room temperature. Carbon-enriched metastable retained austenite is considered beneficial, because the TRIP phenomenon during the deformation can significantly contribute to the formability and energy absorption of the material.

Recently, Speer et al..$^{[1,2]}$ proposed a novel heattreatment concept, the so-called "quenching and partitioning" (Q\&P) process, for the development of multiphase steels with considerable retention of austenite in the microstructure. The Q\&P process consists of a first quench (quenching step) to a temperature below the martensite-start $\left(M_{s}\right)$ temperature but above the martensite-finish $\left(M_{f}\right)$ temperature, to form a mixture of martensite and austenite, and a subsequent isothermal treatment (partitioning step) at the same temperature

M.J. SANTOFIMIA, Postdoctoral Researcher, and L. ZHAO, Research Fellow, Department of Materials Science and Engineering, Delft University of Technology, are with the Materials Innovation Institute (M2i), 2628 CD Delft, The Netherlands. J. SIETSMA, Associate Professor, is with the Department of Materials Science and Engineering, Delft University of Technology, 2628 CD Delft, The

Netherlands. Contact e-mail: m.santofimianavarro@m2i.nl

Manuscript submitted March 26, 2008.

Article published online November 14, 2008 (one-step treatment) or at a higher temperature (twostep treatment), in order to transfer the carbon from the supersaturated martensite into the austenite. In this heat treatment, alloying elements such as silicon and aluminum are also used, to avoid the carbide precipitation during the partitioning step, because carbide precipitation acts as a sink of carbon that is no longer available for the stabilization of the austenite. Combining this heat treatment with a previous partial austenitization, a microstructure consisting of ferrite, carbon-depleted martensite, and carbon-enriched retained austenite is obtained. This microstructure can lead to an interesting combination of mechanical properties ${ }^{[3,4]}$ from a good formability, as a result of the TRIP effect from the retained austenite, to a strength higher than that of conventional TRIP steels, due to the presence of martensite instead of bainite.

The design of adequate $\mathrm{Q} \& \mathrm{P}$ heat treatments requires an understanding of all the phenomena that can affect the final microstructure of the material during this processing route. Most of the research on the Q\&P process has been focused on treatments that start with full austenitization; ${ }^{[5,6]}$ the use of partial austenitization has been studied less. ${ }^{[1]}$ Therefore, there is insufficient experimental evidence that the phenomena affect the microstructure during the $\mathrm{Q} \& \mathrm{P}$ process in the case of treatments starting with partial austenitization. In this work, the Q\&P process is studied in a low-carbon steel containing $1.1 \mathrm{wt}$ pct aluminum, by the application of partial austenitization followed by quenching to $125^{\circ} \mathrm{C}$, $150{ }^{\circ} \mathrm{C}$, or $175^{\circ} \mathrm{C}$ and partitioning at $250{ }^{\circ} \mathrm{C}$ or $350{ }^{\circ} \mathrm{C}$ for different times. The use of a steel with a chemical composition similar to the typical chemistry of a TRIP steel will help evaluate whether such compositions are suitable for application of the Q\&P process. 
The resulting microstructures have been analyzed by optical and scanning electron microscopy, magnetic measurements, and X-ray diffraction (XRD). The investigation pays attention to the evolution of the microstructure along the whole process, but focuses on the austenite retention.

\section{EXPERIMENTAL PROCEDURE}

The chemical composition of the material used in this work is shown in Table I. The as-received commercial material was a 1.2-mm-thick steel sheet with a multiphase microstructure consisting of ferrite, bainite, and retained austenite. After removing the galvanized layer, dilatometry specimens with dimensions of $1 \times 5 \times$ $10 \mathrm{~mm}^{3}$ were machined. Heat treatments were applied to the specimens with a DT1000 high-resolution dilatometer (Adamel Lhomargy SAS, Roissy en Brie, France). The thermal schedules applied to the specimens are displayed in Figure 1. Specimens were heated at $5{ }^{\circ} \mathrm{C} / \mathrm{s}$, partially austenitized at $900{ }^{\circ} \mathrm{C}$ for 10 minutes, and cooled at $100{ }^{\circ} \mathrm{C} / \mathrm{s}$ to $125^{\circ} \mathrm{C}, 150{ }^{\circ} \mathrm{C}$, or $175^{\circ} \mathrm{C}$ to get a partial martensitic microstructure. Specimens were reheated and isothermally held at $250{ }^{\circ} \mathrm{C}$ or $350{ }^{\circ} \mathrm{C}$ (partitioning temperatures) for different times before quenching to room temperature. In order to select appropriate quenching temperatures, the $M_{s}$ temperature corresponding to the remaining intercritical austenite after the partial austenitization was measured by dilatometry from the direct-quench treatment (Figure 2), leading to $M_{s}=260{ }^{\circ} \mathrm{C}$. The formation of a new phase was also observed. As will be explained in the following Section III, this new phase is identified as epitaxial ferrite.

The specimens were ground and polished according to the usual techniques. The etching procedure proposed by De et al. ${ }^{[7]}$ was applied to the specimens to be observed by light optical microscopy. This etching is a two-step procedure that consists of a first etching in a solution of 5 pct picric acid with a few drops of hydrochloric acid (20 seconds), followed by a second etching in 10 pet aqueous sodium metabisulfide $(8 \mathrm{sec}$ onds). Specimens were also analyzed after etching with 5 pct nital with a JEOL* JSM-6500F field-emission gun

*JEOL is a trademark of Japan Electron Optics Ltd., Tokyo.

scanning electron microscope (FEG-SEM) operating at $15 \mathrm{kV}$.

Some selected specimens were metallographically prepared for electron backscattered diffraction (EBSD) examination with a final polishing step of $0.5 \mathrm{~mm}$, using

Table I. Chemical Composition of the Studied Steel (Weight Percent)

\begin{tabular}{ccccc}
\hline C & Mn & Si & Al & P \\
\hline 0.19 & 1.61 & 0.35 & 1.10 & 0.09 \\
\hline
\end{tabular}

an oxide polishing solution (OPS) suspension. The last specimen-preparation step was electrolytic polishing with an electrolyte consisting of $78 \mathrm{ml}$ perchloric acid, $90 \mathrm{ml}$ distilled water, $730 \mathrm{ml}$ ethanol, and $100 \mathrm{ml}$ butylglycol at $40 \mathrm{~V}$ for 10 seconds. The specimens were analyzed by an orientation imaging microscope attached to a Nova 600 Nanolab dual-beam focused-ion-beam microscope (FEI Company, Hillsboro, OR) equipped with a FEG-SEM column. The analysis was performed under the following conditions: acceleration voltage of $20 \mathrm{kV}$, working distance of $7 \mathrm{~mm}$, tilt angle of $70 \mathrm{deg}$, and step size of $50 \mathrm{~nm}$. The EBSD measurements were carried out in the cross section of the specimens, in a plane perpendicular to the normal direction of the sheet. The orientation data were postprocessed with Channel 5 software provided by HKL Technology (Oxford Instruments, Abingdon, UK).

Cubic specimens with an edge dimension of $1.0 \mathrm{~mm}$ for magnetic measurements were machined from dilatometry specimens using an electrodischarging machine. A 7307 vibrating sample magnetometer (Lake Shore Cryotonics, Westerville, $\mathrm{OH}$ ), calibrated with a standard National Institute of Standards and Technology nickel specimen, was used for the experiments. With this equipment, magnetization curves at room temperature were measured by a stepwise change in the applied

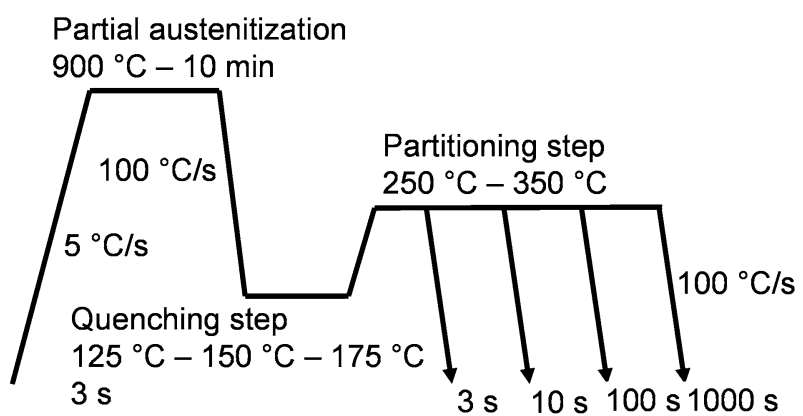

Fig. 1-Scheme of the Q\&P treatments applied to the steel.

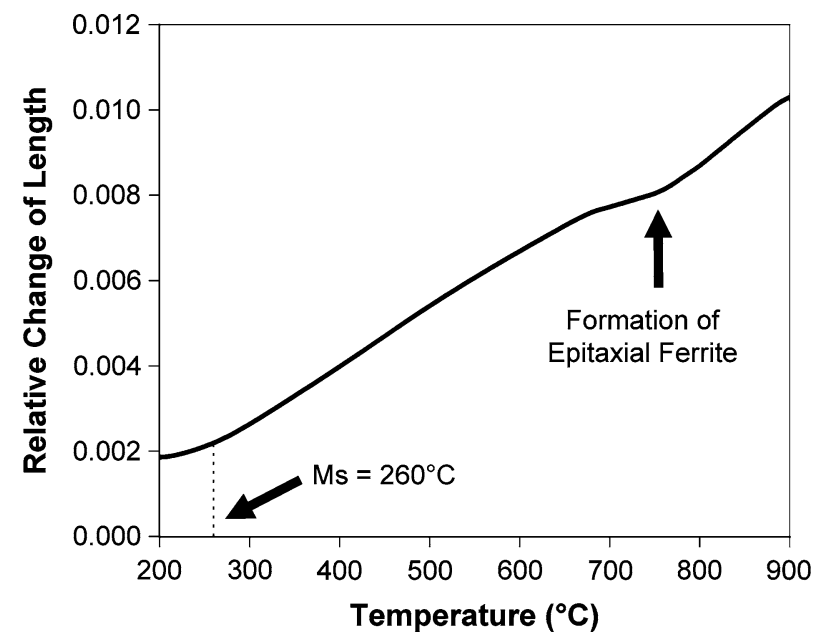

Fig. 2-Dilatometry curve corresponding to the cooling step of the specimen obtained after direct quench at $100{ }^{\circ} \mathrm{C} / \mathrm{s}$ from the intercritical conditions. 
magnetic field from 2.0 to $-2.0 T$. The saturation magnetization values were obtained by fitting the approach to the saturation of the experimentally obtained magnetization curve. ${ }^{[8]}$ The volume fraction of retained austenite in every specimen, $f_{\gamma}$, is determined by comparing the saturation magnetization values obtained both on the specimen with retained austenite, $M_{\text {sat }}(\gamma)$, and on an austenite-free specimen, $M_{\text {sat }}(f)$, according to

$$
f_{\gamma}=1-\beta \frac{M_{\mathrm{sat}}(\gamma)}{M_{\mathrm{sat}}(f)}
$$

The coefficient $\beta$ is obtained via the relation ${ }^{[8]}$

$$
\beta=1-f_{\theta}+f_{\theta}\left[\frac{M_{\mathrm{sat}}^{\theta}}{M_{\mathrm{sat}}^{\alpha}}\right]
$$

where $f_{\theta}$ is the volume fraction of cementite present in the austenite-free specimen, $M_{\text {sat }}^{\alpha}$ is the saturation magnetization of the ferrite, ${ }^{[9]}$ and $M_{\text {sat }}^{\theta}$ is the saturation magnetization of the cementite. ${ }^{[10,11]}$ The austenite-free specimen was obtained by annealing one of the austenite-containing specimens at $600{ }^{\circ} \mathrm{C}$ for 1 hour.

In order to determine the average carbon content of the austenite, XRD experiments were performed on a Bruker-type D8-Advance diffractometer (Bruker AXS, Karlsruhe, Germany) equipped with a Bruker VANTEC position sensitive detector. In the experiments, Co $K_{\alpha}$ radiation was used; a $2 \theta$ range from 30 to $135 \mathrm{deg}$, containing the (111), (200), (220), and (311) austenite reflections, was scanned using a step size of $0.05 \mathrm{deg}$. The austenite lattice parameter, $a_{\gamma}$, was determined from the peak position of each austenite reflection using Cohen's method. ${ }^{[12]}$ The carbon concentration $x_{\mathrm{C}}$ of the austenite was obtained using the relation ${ }^{[13]}$

$$
a_{\gamma}=0.3556+0.00453 x_{\mathrm{C}}+0.000095 x_{\mathrm{Mn}}+0.00056 x_{\mathrm{A} 1}
$$

where $x_{\mathrm{C}}, x_{\mathrm{Mn}}$, and $x_{\mathrm{Al}}$ are the concentrations of carbon, manganese, and aluminum, respectively, in austenite, in weight percent. The effects of silicon and phosphorus are not considered in Eq. [2], although the effects of substitutional elements on the lattice parameter are small compared with the influence of the carbon content, as can also be observed from Eq. [3]. The results of this calculation indicate an average measurement of the carbon content in the austenite.

\section{RESULTS}

\section{A. Optical Microscopy}

Figure 3 shows the optical microscopy micrographs of the specimens quenched to $175^{\circ} \mathrm{C}$ and partitioned at $350{ }^{\circ} \mathrm{C}$ for 3 and 1000 seconds. These micrographs are used here to describe common microstructural details observed for different quenching and partitioning temperatures. According to the work of De et al., ${ }^{[7]}$ their proposed etching procedure allows the identification of retained austenite in TRIP and dual-phase microstructures by the revelation of white islands clearly different from the ferrite phase. However, as has been analyzed in a previous study, ${ }^{[14]}$ the distinction between martensite and austenite from the metallographic study using this agent is not clear in this material. In the present case, retained austenite and untempered martensite are observed as light-colored islands in a ferritic matrix, whereas tempered martensite and bainite are observed in a dark color because of the finer microstructure and, in some cases, the presence of carbide precipitation.

From the figures, the mixture of untempered martensite and retained austenite is observed to be more abundant in the specimen partitioned for 3 seconds than in the specimen partitioned for 1000 seconds. On the other hand, the combination of tempered martensite and bainite is more abundant in the specimen partitioned for 1000 seconds. This observation is in agreement with the occurrence, at longer partitioning times, of conventional martensite tempering processes such as carbide precipitation in martensite and decomposition of austenite into bainite. This observation is analyzed in the following Section III-B.

In Figures 3(a) and (b), ferrite is clearly observed as the white matrix, but a detailed observation shows very
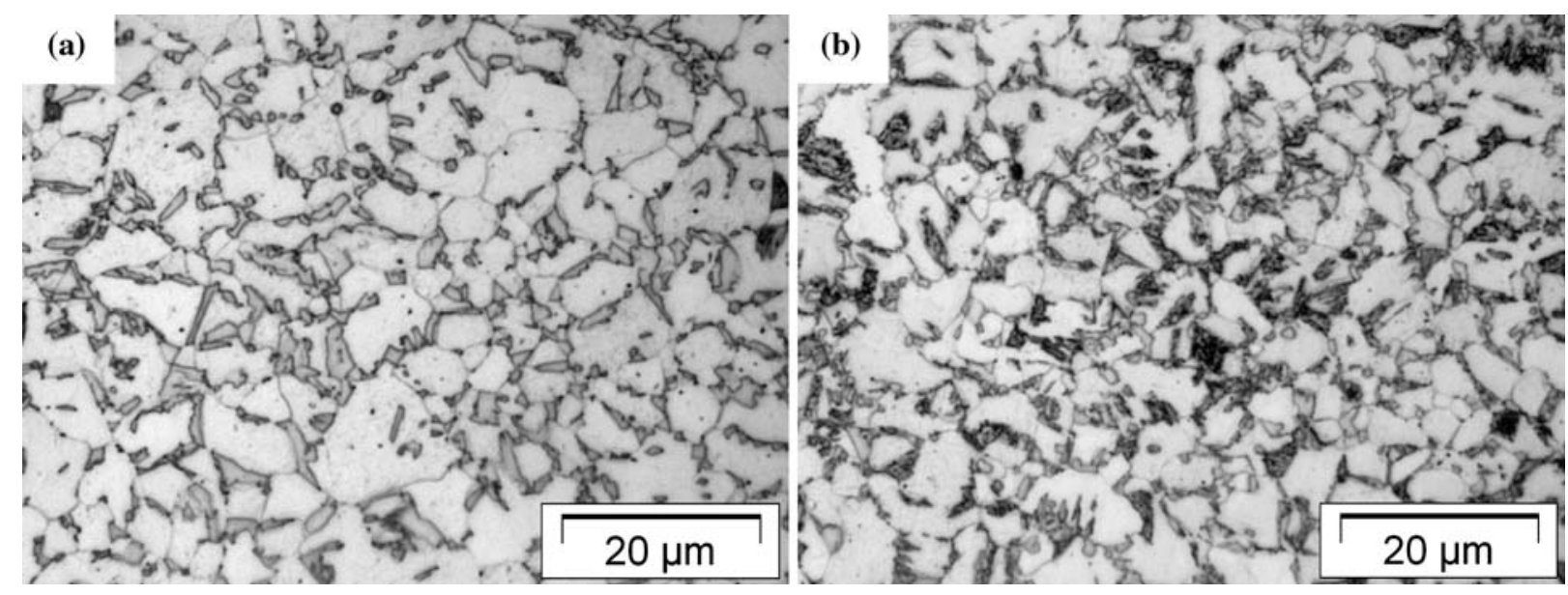

Fig. 3- Microstructure after Q\&P heat treatments with quenching at $175{ }^{\circ} \mathrm{C}$ and partitioning at $350{ }^{\circ} \mathrm{C}$ for $(a) 3 \mathrm{~s}$ and $(b) 1000 \mathrm{~s}$. 
fine boundaries separating ferrite areas inside the same well-defined ferrite grain. The ferritic areas that are closer to the austenite/martensite grains correspond to ferrite that has grown from the ferrite present after the intercritical treatment during the first cooling (the socalled epitaxial ferrite $\left.{ }^{[15,16]}\right)$. A detailed characterization of the epitaxial ferrite formed during cooling in this material can be found elsewhere. ${ }^{[14]}$ Moreover, more details of the formation of epitaxial ferrite in this material will be presented in the following Section III-B, III-C.

Optical microscopy observations give indications about the microstructure present in the specimens for every Q\&P condition. However, they do not provide microstructural details smaller than a few microns; therefore, scanning electron microscopy has been used for these purposes.

\section{B. Scanning Electron Microscopy}

Epitaxial ferrite can also be distinguished by scanning electron microscopy. As an example, Figure 4 shows the microstructure of the specimen quenched at $125^{\circ} \mathrm{C}$ and tempered at $350{ }^{\circ} \mathrm{C}$ for 10 seconds, as observed by FEG-SEM. Epitaxial ferrite is clearly distinguished from intercritical ferrite because of a different topography. This means that intercritical and epitaxial ferrite have a different response to the 5 pct nital etching. These differences are due to a distinct composition of substitutional alloying elements in each type of ferrite, because epitaxial ferrite has grown during rapid cooling under paraequilibrium conditions with the austenite, ${ }^{[15,17]}$ whereas the partitioning of alloying elements was possible to a certain extent during the intercritical annealing.

From scanning electron microscopy observations, no substantial differences have been detected in the microstructures observed after partitioning at $250{ }^{\circ} \mathrm{C}$ for every quenching temperature. In particular, Figures 5(a) and (b) show the microstructures of the specimens quenched at $125^{\circ} \mathrm{C}$ and partitioned at $250{ }^{\circ} \mathrm{C}$ for 3 and
100 seconds. A comparison of these figures shows that there has not been any substantial tempering of the martensitic microstructure during partitioning at $250{ }^{\circ} \mathrm{C}$ for less than 100 seconds. However, carbide precipitation is observed in specimens partitioned for $1000 \mathrm{sec}-$ onds at this temperature, as shown in Figure 5(c) and (d) for the specimen quenched at $125^{\circ} \mathrm{C}$.

The characteristic tempering phenomena occurring in the martensite at $350{ }^{\circ} \mathrm{C}$ are different from those occurring at $250{ }^{\circ} \mathrm{C}$. In addition, the carbon partitioning from martensite to austenite is faster at $350{ }^{\circ} \mathrm{C}$ than at $250{ }^{\circ} \mathrm{C}$. These changes in the kinetics of the processes should be reflected in the characteristics of the microstructure of the specimens partitioned at $350{ }^{\circ} \mathrm{C}$. In this vein, Figure 6(a) shows the microstructure of the specimen quenched at $125^{\circ} \mathrm{C}$ and partitioned at $350{ }^{\circ} \mathrm{C}$ for 10 seconds, in which blocks of tempered and untempered martensite in a ferrite matrix are observed. One of the blocks of tempered martensite is enlarged in Figure 6(b), showing carbide precipitation. These two figures provide evidence that 10 seconds of partitioning at $350{ }^{\circ} \mathrm{C}$ is enough time to start the tempering of the microstructure. Similar behavior has been observed after quenching at $150{ }^{\circ} \mathrm{C}$ and $175^{\circ} \mathrm{C}$.

After partitioning for 1000 seconds at $350{ }^{\circ} \mathrm{C}$, bainite has been observed in all the specimens. The resulting bainitic microstructure, shown in Figure 7, is formed by bainitic ferrite plates separated by films of retained austenite or martensite formed during the final quench. Figure 7(a) displays the microstructure of the specimen quenched to $150{ }^{\circ} \mathrm{C}$ and partitioned at $350{ }^{\circ} \mathrm{C}$ for 1000 seconds, showing a high fraction of bainite. Figure 7(b) contains an enlarged micrograph of the square area drawn in Figure 7(a), showing details of the decomposition of residual austenite in bainite. Figures 7(c) and (d) show the presence of bainite in the specimens quenched to $125^{\circ} \mathrm{C}$ and $175^{\circ} \mathrm{C}$, respectively, and partitioned at $350{ }^{\circ} \mathrm{C}$ for 1000 seconds. In all the observed cases, bainitic ferrite plates are free of internal cementite particles, which is characteristic of upper bainite.
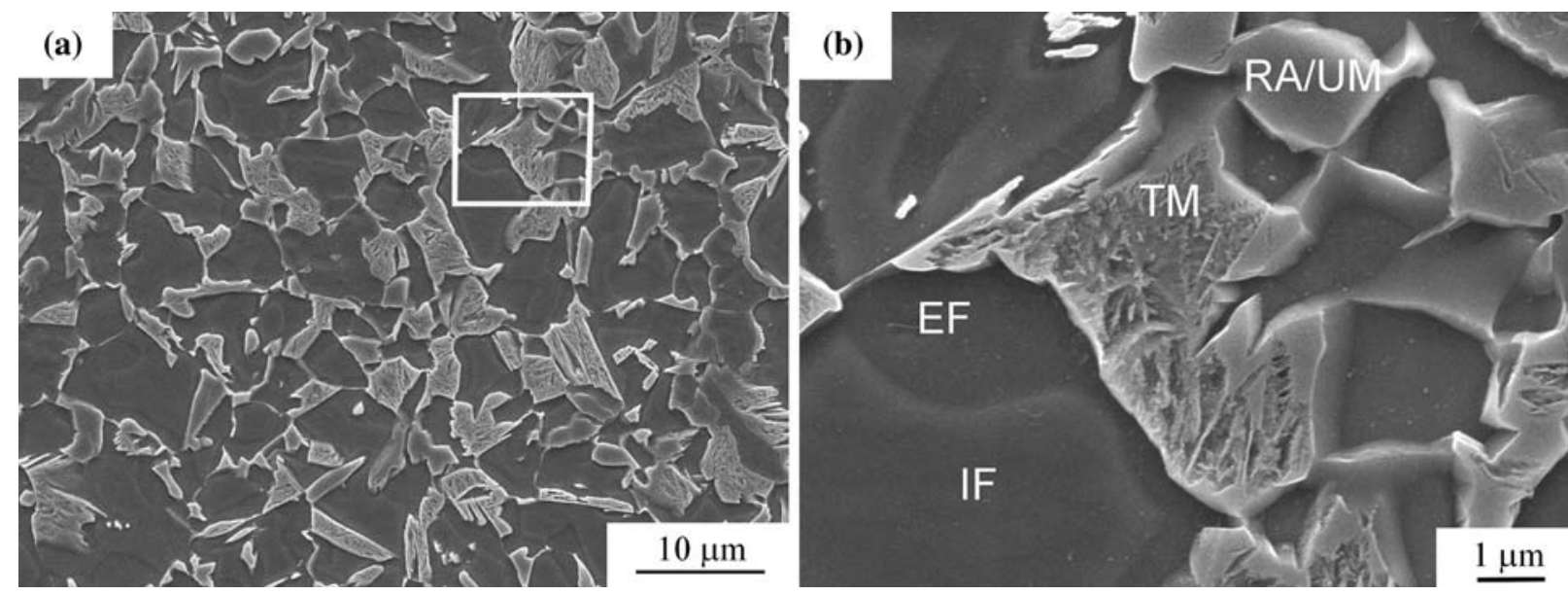

Fig. 4-(a) and (b) FEG-SEM micrographs of a specimen quenched to $125^{\circ} \mathrm{C}$ and partitioned at $350{ }^{\circ} \mathrm{C}$ for $10 \mathrm{~s}$. The square in (a) is enlarged in (b). (EF is epitaxial ferrite, IF is intercritical ferrite, TM is tempered martensite, and RA/UM is retained austenite or untempered martensite). 

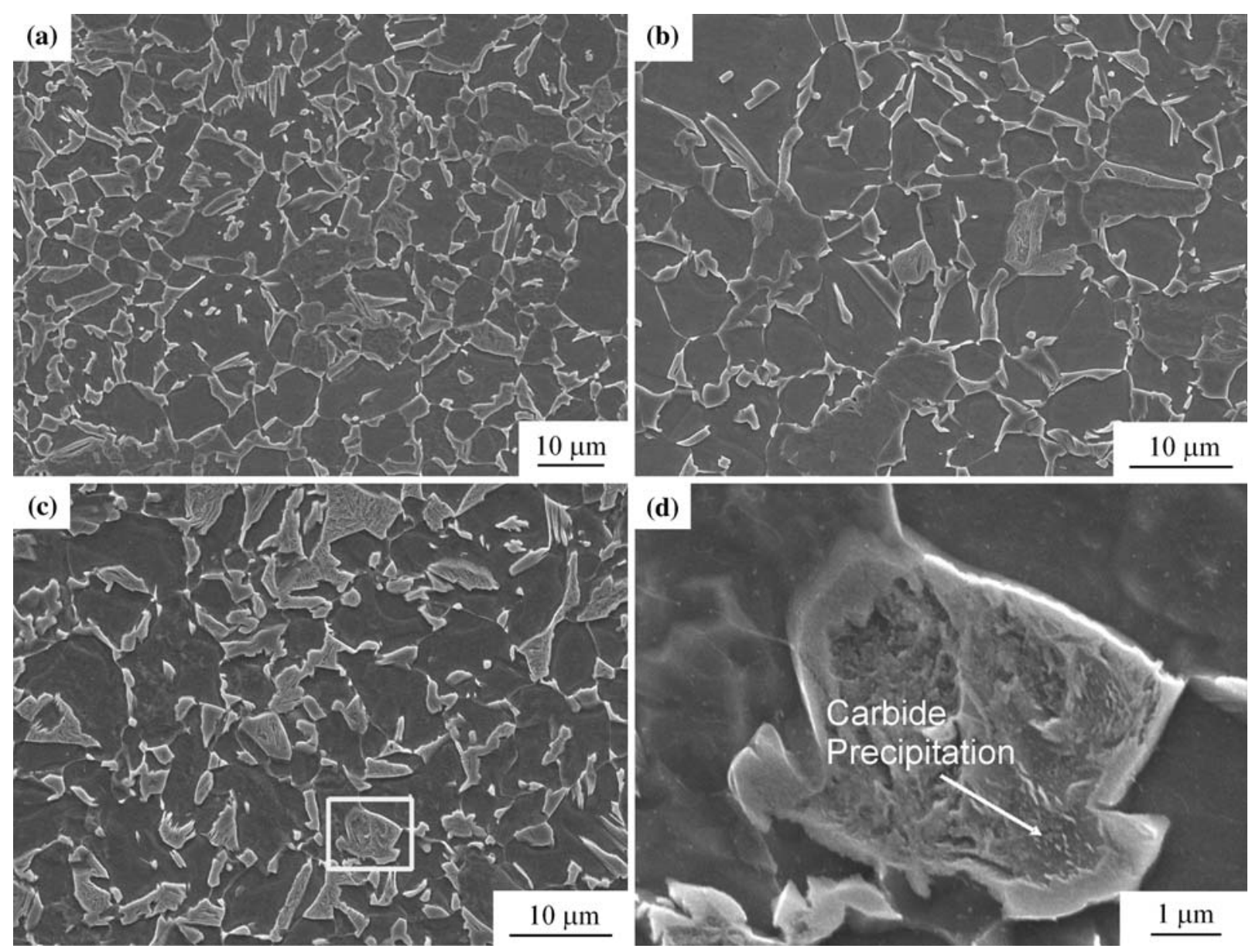

Fig. 5-FEG-SEM micrographs of specimens quenched to $125^{\circ} \mathrm{C}$ and partitioned at $250{ }^{\circ} \mathrm{C}$ for $(a) 3 \mathrm{~s},(b) 100 \mathrm{~s}$, and $(c)$ and $(d) 1000 \mathrm{~s}$. The square in (c) is enlarged in (d), showing a block of tempered martensite containing carbide precipitation.
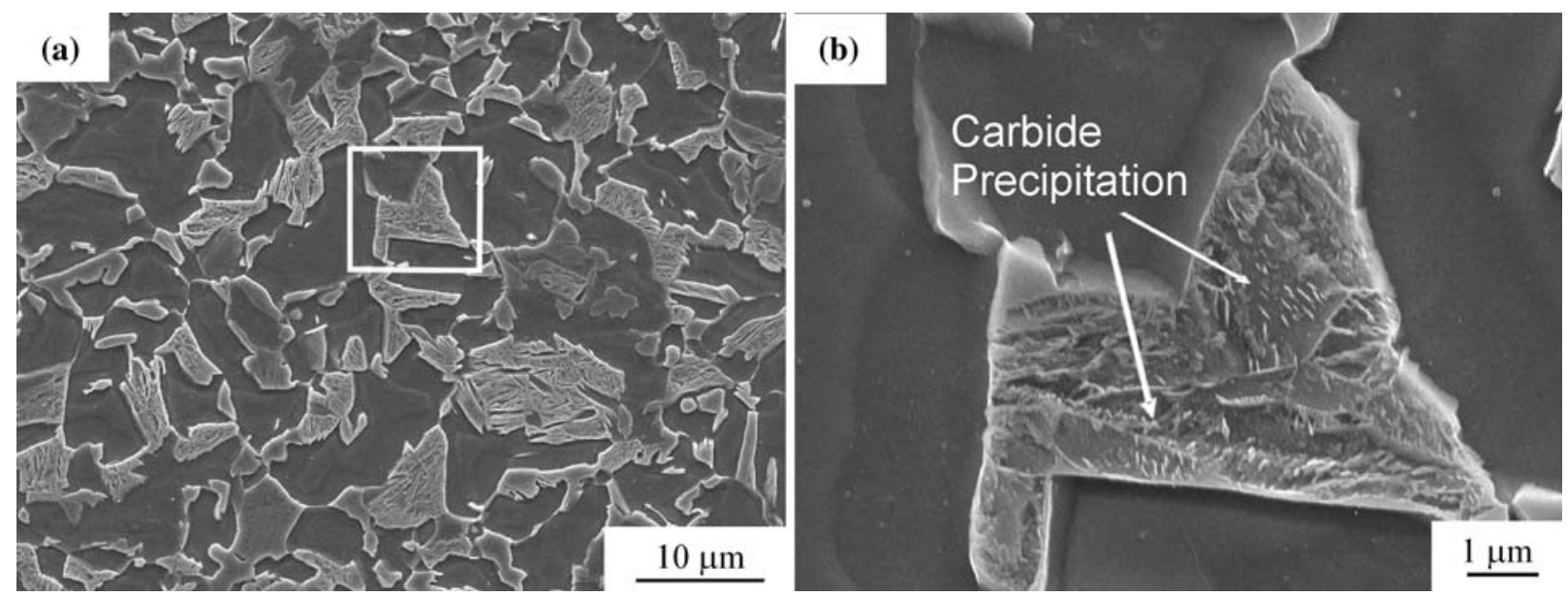

Fig. 6- (a) and (b) FEG-SEM micrographs of a specimen quenched to $125^{\circ} \mathrm{C}$ and partitioned at $350{ }^{\circ} \mathrm{C}$ for $10 \mathrm{~s}$. The square in (a) is enlarged in (b), showing a block of tempered martensite containing carbide precipitation.

\section{Electron Backscattered Diffraction}

In order to support some of the microstructural features mentioned, an EBSD analysis was performed on the specimens quenched to $150{ }^{\circ} \mathrm{C}$ and partitioned at $350{ }^{\circ} \mathrm{C}$ for 10 and 1000 seconds.
Figure 8(a) shows a scanning electron microscopy image of the EBSD scan displayed in Figure 8(b) of the specimen quenched to $150{ }^{\circ} \mathrm{C}$ and partitioned at $350{ }^{\circ} \mathrm{C}$ for 10 seconds. In particular, Figure 8(b) is a combined band-contrast (BC) map and color-coded phase map, in 

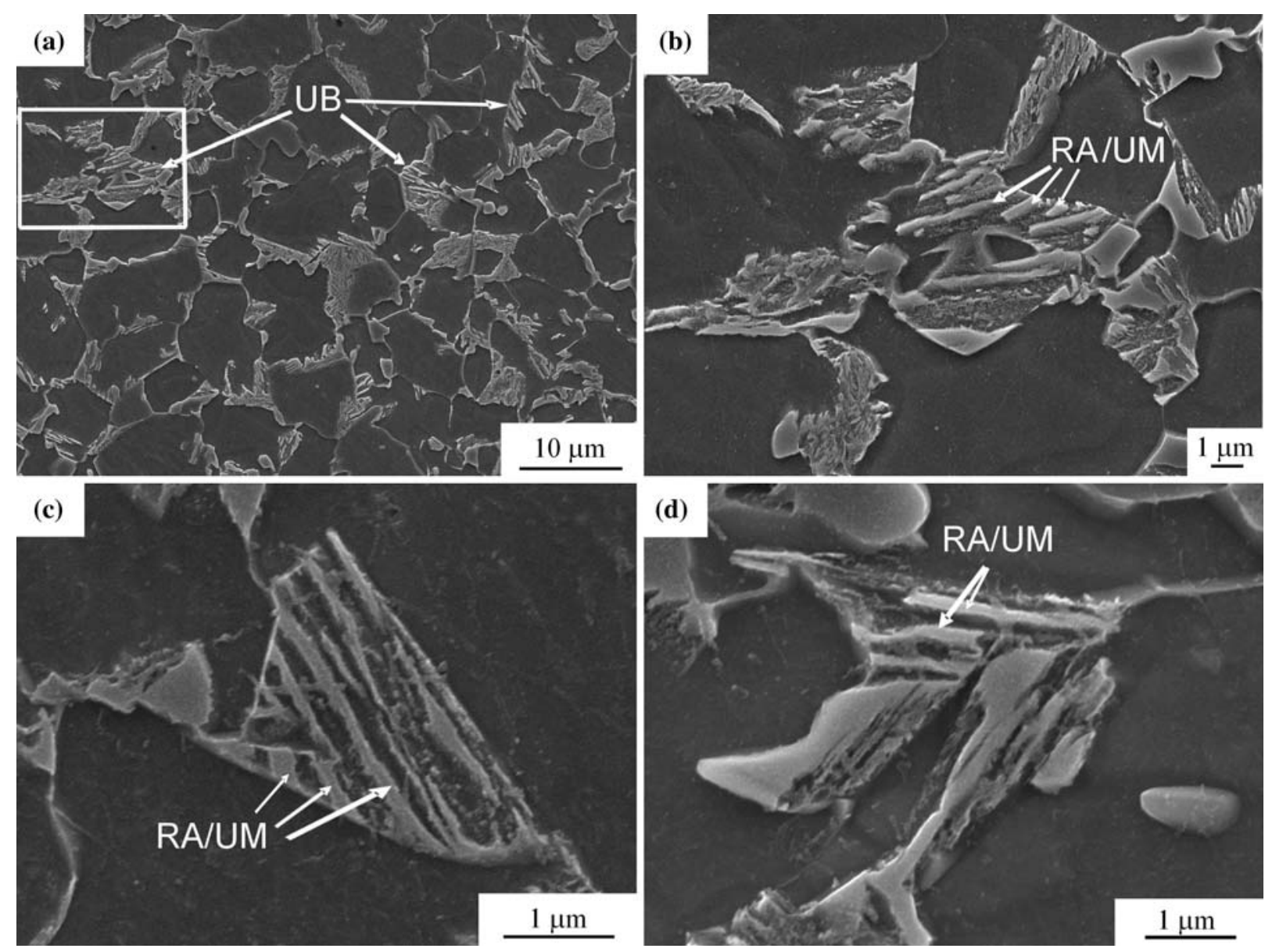

Fig. 7-FEG-SEM micrographs of specimens partitioned at $350{ }^{\circ} \mathrm{C}$ for $1000 \mathrm{~s}:(a)$ microstructure of specimen quenched at $150{ }^{\circ} \mathrm{C}$, $(b)$ detail of bainite corresponding to the square drawn in (a), $(c)$ bainite in specimen quenched at $125^{\circ} \mathrm{C}$, and $(d)$ bainite in specimen quenched at $175{ }^{\circ} \mathrm{C}$. (UB is upper bainite, TM is tempered martensite, and RA/UM is retained austenite or untempered martensite).

which blue corresponds to bcc lattice, red corresponds to fcc lattice, and darker areas correspond to a very low BC, most probably indicating martensite. Retained austenite is observed with an equiaxed morphology and is situated very close to martensite, near the ferrite boundaries.

A similar combination of figures is shown in Figure 9, for the specimen quenched to $150{ }^{\circ} \mathrm{C}$ and partitioned at $350{ }^{\circ} \mathrm{C}$ for 1000 seconds. In this case, austenite is observed with a filmy morphology and surrounded by ferrite. This microstructure resembles, in morphology and size, the one presented in Figure 7 and identified as bainite. This austenite morphology was not observed after partitioning for 10 seconds and reinforces the microstructural interpretation done in previous Section III-A, III-B.

The arrows in Figure 9(a) indicate the presence of epitaxial ferrite. Figure 10(a) shows a combined BC and orientation image map of the microstructure analyzed in Figure 9. It is clear that epitaxial ferrite shares the grain orientation with the surrounding ferrite. Moreover, the point-to-origin misorientation profile along the black straight line shown in Figure 10(a) was analyzed, with point 1 being the origin of the analysis. The resulting misorientation profile is shown in Figure 10(b). The misorientation between the two neighboring ferrite grains analyzed does not show significant changes when the boundaries between intercritical and epitaxial ferrite are reached. This observation confirms the formation of epitaxial ferrite by the growth of the intercritical ferrite in the absence of nucleation.

\section{XRD and Magnetic Measurements}

One of the desired goals in the Q\&P process is obtaining multiphase microstructures with an adequate volume fraction and adequate carbon enrichment of the retained austenite. Therefore, the characterization of the retained austenite in volume fraction and carbon content is of pre-eminent importance in this investigation.

Figures 11(a) and (b) show the volume fraction of retained austenite (measured by the magnetization method) and its carbon content (from XRD) in the specimens thermally treated with a partitioning temperature of $250{ }^{\circ} \mathrm{C}$. The horizontal solid line represents the corresponding measurements in the specimen directly quenched. The volume fraction of retained austenite for all the quenching temperatures and partitioning times is rather close to the one measured in the specimen directly quenched, leading to values between 0.03 and 0.06 . Carbon content measurements are also close to the 


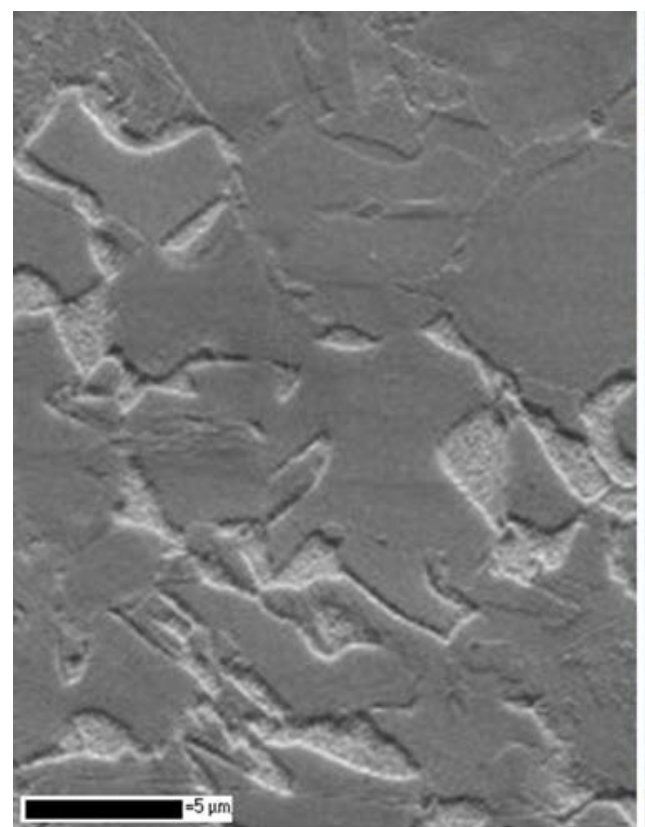

(a)

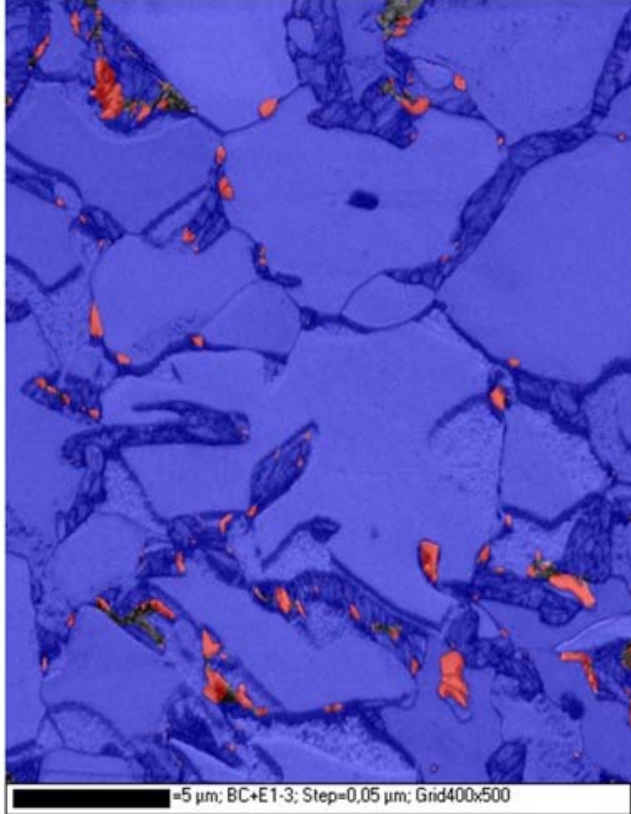

(b)

Fig. 8-EBSD analysis of the sample quenched to $150{ }^{\circ} \mathrm{C}$ and partitioned at $350{ }^{\circ} \mathrm{C}$ for $10 \mathrm{~s}$ : (a) secondary electron image of the scan analysis; and (b) combined BC map and color-coded phase map corresponding to the scan shown in (a), in which blue corresponds to bcc lattice, red corresponds to fcc lattice, and darker areas correspond to a very low $\mathrm{BC}$, most probably indicating martensite.

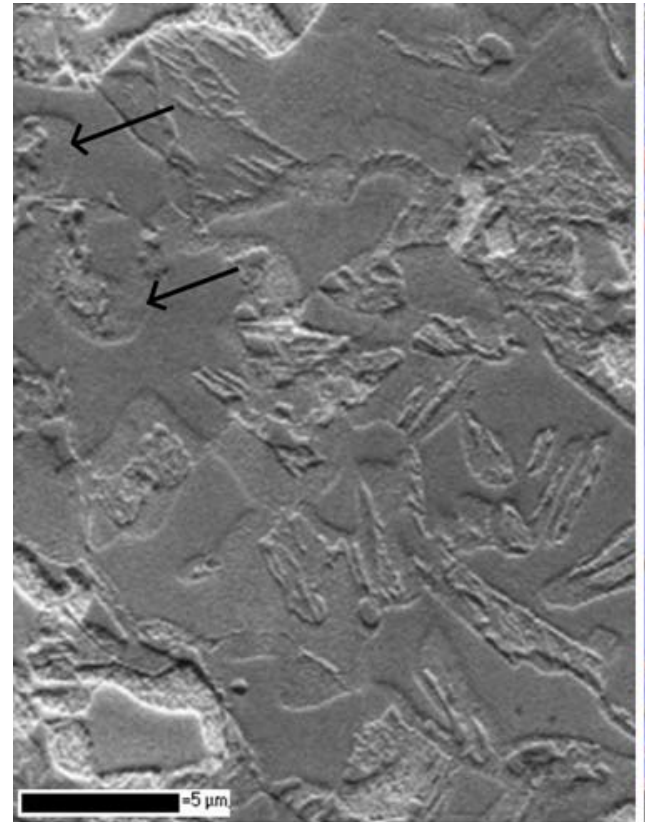

(a)

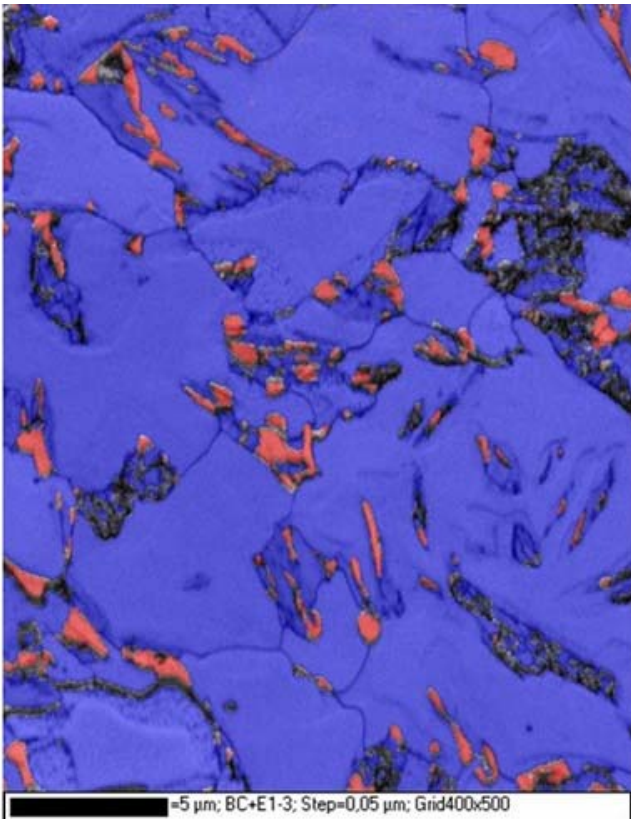

(b)

Fig. 9-EBSD analysis of the sample quenched to $150{ }^{\circ} \mathrm{C}$ and partitioned at $350{ }^{\circ} \mathrm{C}$ for $1000 \mathrm{~s}$ : $(a)$ secondary electron image of the scan analysis; and (b) combined BC map and color-coded phase map corresponding to the scan shown in (a), in which blue corresponds to bcc lattice, red corresponds to fcc lattice, and darker areas correspond to a very low $\mathrm{BC}$, most probably indicating martensite.

value obtained in the direct-quenched specimen and are approximately constant along the partitioning times, with a slight tendency to decrease in the case of partitioning for 1000 seconds.
The same measurements corresponding to the specimens treated with a partitioning temperature of $350{ }^{\circ} \mathrm{C}$ are presented in Figures 11(c) and (d). In this case, some common tendencies are observed for every quenching 


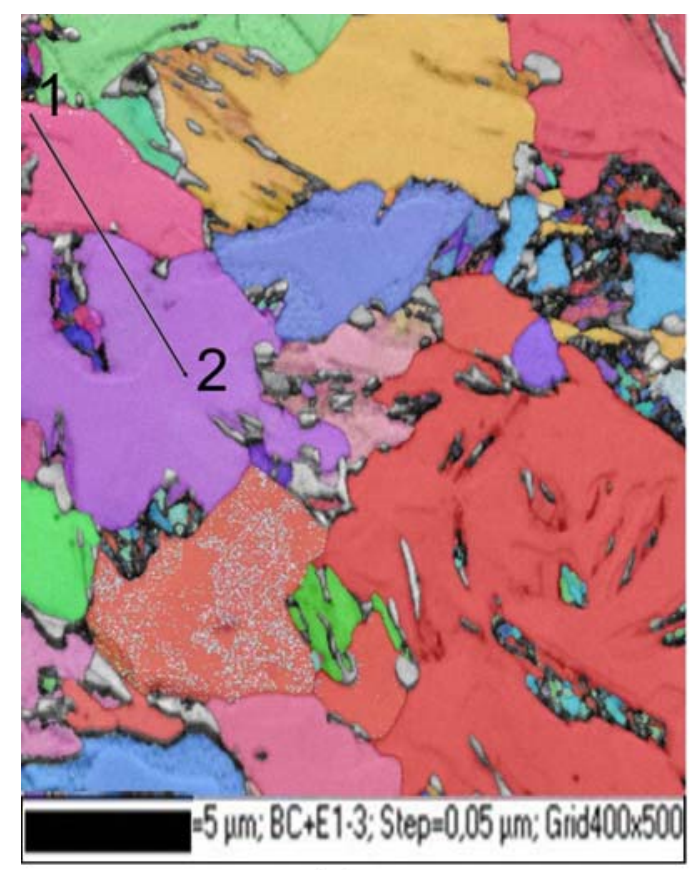

(a)

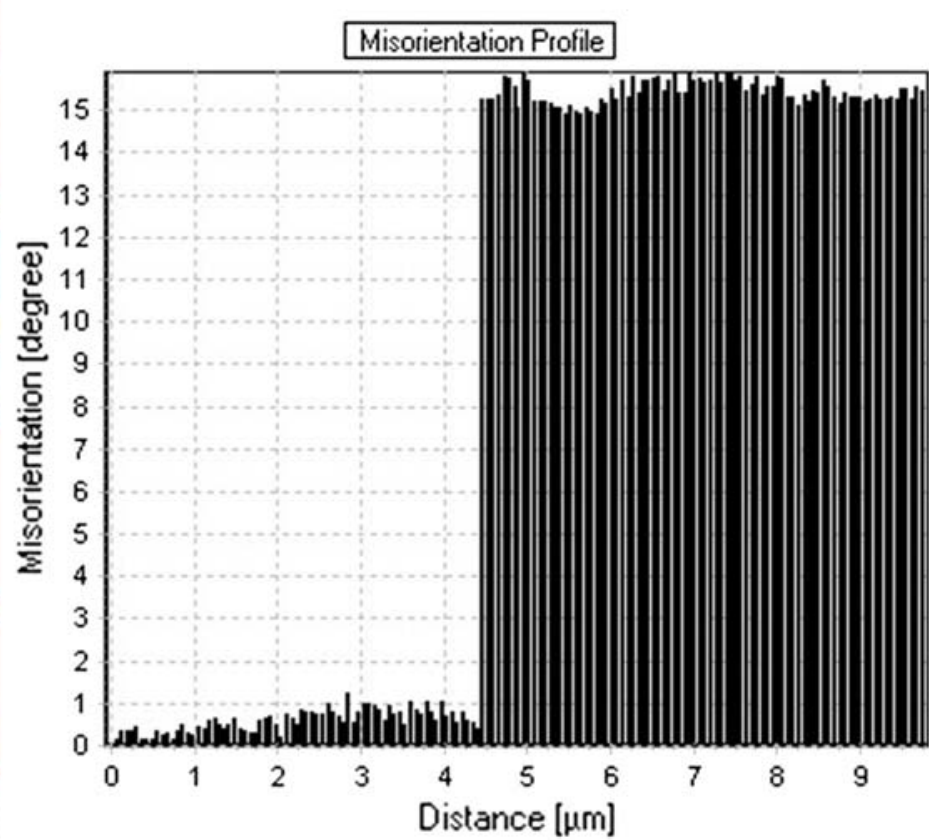

(b)

Fig. 10-(a) Combined BC and orientation image map of the microstructure analyzed in Fig. 9 and $(b)$ misorientation measured with respect to the first point along the line shown in (a).

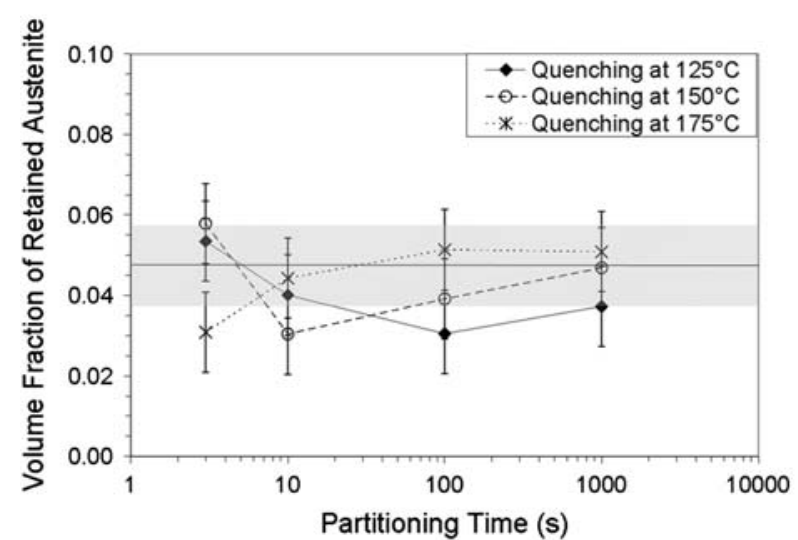

(a)

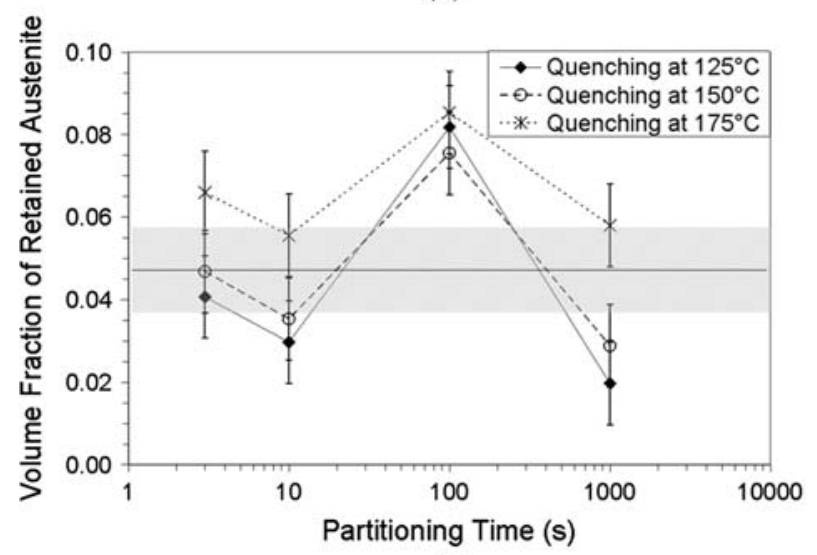

(c)

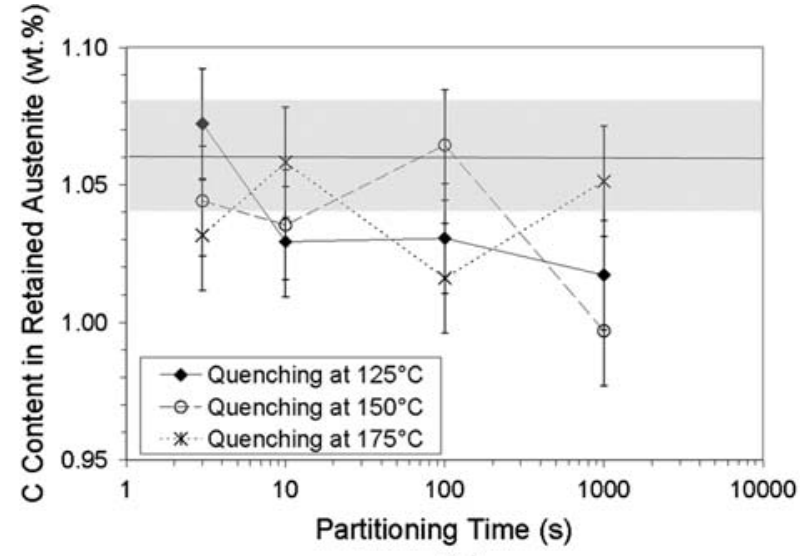

(b)

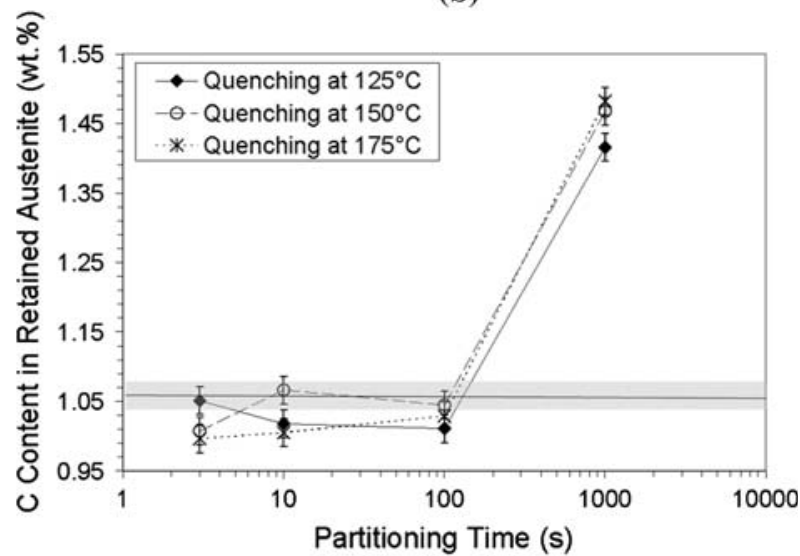

(d)

Fig. 11-(a) Volume fraction and $(b)$ carbon content of retained austenite, for Q\&P heat treatments with partitioning at $250{ }^{\circ} \mathrm{C}$; $(c)$ volume fraction of retained austenite; and $(d)$ carbon content for partitioning at $350{ }^{\circ} \mathrm{C}$. The horizontal solid line represents the corresponding measurement in the direct-quenched specimen; shaded areas represent the estimated error of this measurement. 
temperature studied: (1) after the partitioning for 3 and 10 seconds, the volume fraction of austenite and the carbon content are similar to the specimen directly quenched, with a slight decrease in volume fraction at 10 seconds, in comparison to the result at 3 seconds; (2) there is a substantial increase in the volume fraction of austenite after partitioning for 100 seconds, without changes in the carbon content; and (3) at 1000 seconds of partitioning, there is a decrease in the volume fraction of austenite, with an obvious increase in its carbon content.

\section{DISCUSSION}

\section{A. Cooling from Intercritical Region}

The calculation of the amount of ferrite remaining after the partial austenitization at $900{ }^{\circ} \mathrm{C}$ using MTDATA (National Physical Laboratory, Teddington, UK) leads to a volume fraction equal to 0.34 . However, the amount of ferrite found experimentally was $0.74 \pm 0.05$, which is almost two times greater than the amount expected from this calculation. This important discrepancy originates from the formation of epitaxial ferrite.

The formation of epitaxial ferrite during the cooling step of the heat treatments has important implications in the subsequent microstructure before the partitioning step. As schematically represented in Figure 12, epitaxial ferrite formation introduces carbon gradients in the remaining austenite during the first cooling step, leading to more carbon enrichment close to the austenite boundaries and less carbon in areas well inside the austenite grains. As a result, martensite formed at the quenching temperature will be more likely formed inside the austenite grains, leaving the austenite that is closer to the boundaries untransformed. This morphology can be observed in Figure 5(d), in which the martensite that looks tempered is situated in the center of the former austenite grain. This martensite is formed during the first quench of the Q\&P process and tempered during the partitioning step, while the surrounding austenite remains untransformed. After the second quench, the surrounding austenite is either transformed to (untempered) martensite or retained, in both cases showing a smooth surface by scanning microscopy.

A consequence of this morphology is that the initial carbon content in the martensite and austenite before the partitioning step is not equal; it is higher in the austenite than in the martensite. Therefore, the end of the carbon partitioning from martensite to austenite during the partitioning step will be reached at an earlier stage than is the case when the carbon content is the same in both phases. Moreover, this additional carbon enrichment of the austenite is favorable for stabilizing this phase.

However, an excess of epitaxial ferrite would reduce the amount of martensite formed at the quenching temperature to levels that could not be interesting in terms of the strength of the steel. Therefore, it is important to control the formation of epitaxial ferrite during the quenching step, in order to ensure an adequate volume fraction of austenite before the formation of martensite.

The quenching temperature determines the amount of martensite and austenite prior to the partitioning step. Since the experimental $M_{s}$ temperature is known, the amount of martensite formed after quenching to temperatures of $125^{\circ} \mathrm{C}$ and $175^{\circ} \mathrm{C}$ is estimated by using the Koistinen and Marburger equation. ${ }^{[18]}$ Table II shows the calculated volume fractions of the phases. These estimations show that the volume fraction of austenite

Table II. Estimation of Martensite and Austenite Volume Fractions at Every Quenching Temperature

\begin{tabular}{lcc}
\hline $\begin{array}{l}\text { Quenching } \\
\text { Temperature }\left({ }^{\circ} \mathrm{C}\right)\end{array}$ & $\begin{array}{c}\text { Volume Fraction } \\
\text { of Martensite }\end{array}$ & $\begin{array}{c}\text { Volume Fraction } \\
\text { of Austenite }\end{array}$ \\
\hline 125 & 0.20 & 0.06 \\
150 & 0.18 & 0.08 \\
175 & 0.16 & 0.10 \\
\hline
\end{tabular}

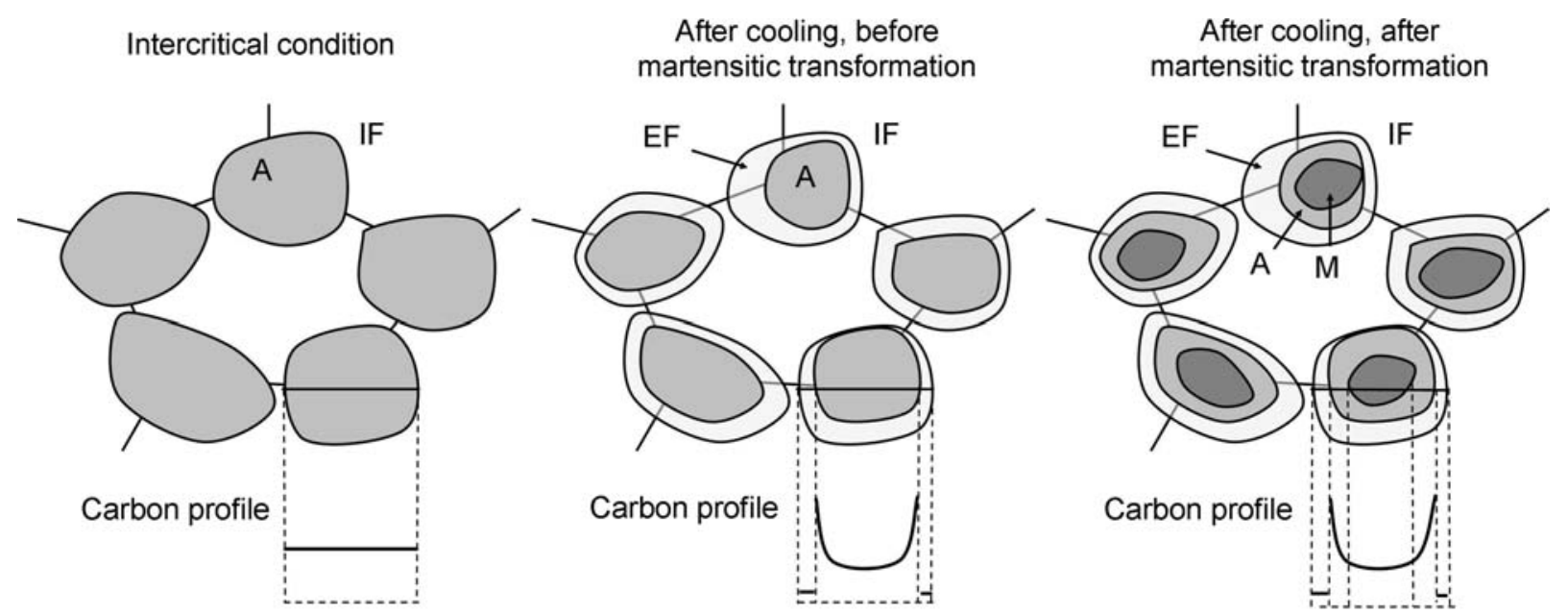

Fig. 12-Scheme of morphology and carbon profiles during different stages of the Q\&P process. (A is austenite, IF is intercritical ferrite, EF is epitaxial ferrite, and $\mathrm{M}$ is martensite.) 
available for further carbon partitioning is limited to values lower than 0.10 in the case of quenching to $175^{\circ} \mathrm{C}$, and lower yet for quenching at $150^{\circ} \mathrm{C}$ and $125^{\circ} \mathrm{C}$, as a consequence of the formation of epitaxial ferrite during cooling.

\section{B. Partitioning at $250{ }^{\circ} \mathrm{C}$}

In a previous study, ${ }^{[19]}$ the present authors have simulated the kinetics of carbon partitioning from martensite to austenite based on the constrained carbon equilibrium assumptions, ${ }^{[20,21]}$ considering the alloy studied in this work. These calculations have been used here to make an interpretation of the experimental results observed for different partitioning temperatures and times. In particular, calculations corresponding to the case of quenching at $125^{\circ} \mathrm{C}$ and $175^{\circ} \mathrm{C}$ and partitioning at $250{ }^{\circ} \mathrm{C}$ showed that the completion of the carbon partitioning and the homogenization of carbon in the austenite are reached after partitioning for approximately $10^{5}$ seconds. Therefore, after partitioning times of 3,10, and 100 seconds, the carbon diffusion is not substantial enough to get an additional carbon enrichment and, consequently, a volume fraction increase in the retained austenite, which is in agreement with the experimental results. Given that, experimentally, the volume fraction and carbon content of the retained austenite is similar to those obtained in the specimen directly quenched, the carbon enrichment of the austenite due to the formation of epitaxial ferrite is probably the process responsible for the austenite retention in these specimens.

As is shown in Figure 5, carbide precipitation was observed in specimens partitioned for 1000 seconds at $250{ }^{\circ} \mathrm{C}$. This carbide precipitation is detrimental to the microstructural characteristics of the material, because it reduces the amount of carbon to be partitioned to the austenite. Carbide precipitation explains the absence of carbon enrichment (and the constant volume fraction) of the austenite in specimens partitioned for 1000 seconds. In particular, this carbide precipitation is probably responsible for the decrease in the carbon content in the austenite in specimens quenched at $125^{\circ} \mathrm{C}$ and $150{ }^{\circ} \mathrm{C}$ after 1000 seconds of partitioning (Figure 11(b)).

As has been shown in Table II, different quenching temperatures lead to slightly different amounts of austenite available for carbon partitioning during the partitioning step. However, apart from small differences in the carbon content of the retained austenite, which are not significant if the error bars are taken into account, no significant differences have been observed between the resulting microstructures formed under different quenching temperatures.

\section{Partitioning at $350{ }^{\circ} \mathrm{C}$}

During partitioning at $350{ }^{\circ} \mathrm{C}$, the volume fraction and carbon content in the austenite show complex variations (Figures 11(c) and (d)) that are independent of the quenching temperature used. The calculations of carbon partitioning kinetics at $350{ }^{\circ} \mathrm{C}$ presented in Reference 19 showed that carbon partitioning from martensite to austenite is in an advanced stage after isothermal treatment for 100 seconds, whereas the completion of the process, including the homogenization of carbon in the austenite, takes place after 1000 seconds. Partitioning during 3 or 10 seconds is not long enough to get considerable carbon enrichment of the austenite and, consequently, not long enough to further stabilize this phase. Therefore, the modeling results can justify that the carbon content and volume fraction of austenite after 3 and 10 seconds of partitioning are similar to those obtained on the specimen directly quenched; this is also true for the increase in the volume fraction observed after 100 seconds of partitioning. Moreover, the initial stages of the carbon partitioning process, from the relatively carbon-rich martensite to austenite, generate steep carbon gradients in the austenite close to the austenite/martensite interface, which can be interpreted as creating possible sites for the formation of carbides. This consideration explains the carbide precipitation in the martensite observed close to the ferrite boundary in the specimen quenched at $125^{\circ} \mathrm{C}$ and partitioned $350{ }^{\circ} \mathrm{C}$ for $10 \mathrm{sec}-$ onds (Figure 4(b)).

After 1000 seconds of partitioning, all the specimens show a decrease in the volume fraction of austenite and a significant increase in the carbon content of the retained austenite. The reason for this behavior is the observed decomposition of the austenite in bainite (Figure 5). Bainite formation takes place through the successive nucleation and diffusionless growth of bainitic ferrite plates that soon afterward partition the excess of carbon to the surrounding austenite. The growth of each bainitic ferrite plate continues until it is stifled by the strength of the residual austenite. ${ }^{[22,23]}$ Cementite could then precipitate from the enriched austenite between the bainitic ferrite plates. However, given that the steel is alloyed with a considerable amount of aluminum, carbide precipitation between the bainitic ferrite plates is likely to be inhibited. Therefore, the carbon that is rejected from the bainitic ferrite enriches the residual austenite, leading to an additional carbon enrichment of this phase that explains the obvious increase in the carbon content experimentally determined after partitioning for 1000 seconds. Moreover, this process involves a reduction in the volume fraction of austenite, because part of the austenite transforms to bainitic ferrite plates.

To understand the formation of bainite at this temperature, the bainite start $\left(B_{S}\right)$ temperature corresponding to the residual austenite just before the martensitic transformation (taking into account the formation of epitaxial ferrite) has been calculated using the procedure proposed by Bhadeshia, ${ }^{[24,25]}$ which includes the effects of $\mathrm{C}, \mathrm{Si}, \mathrm{Al}$, and $\mathrm{Mn}$. This calculation results in $B_{s}=360{ }^{\circ} \mathrm{C}$, which means that a partitioning temperature of $350{ }^{\circ} \mathrm{C}$ is inside the temperature range of the bainite formation and that, therefore, its formation would be possible during the partitioning step, if the conditions for nucleation are favorable.

The thermodynamic method developed by Bhadeshia ${ }^{[26]}$ for the calculation of bainite incubation times, which is 
based on Russell's method, ${ }^{[27]}$ has been used for the estimation of the incubation times for bainite at $250{ }^{\circ} \mathrm{C}$ and $350{ }^{\circ} \mathrm{C}$, considering the chemical composition of the austenite just before the martensitic transformation. Following this method, the incubation time for the formation of bainite is given by

$$
\ln \left|\frac{t\left(\Delta G_{m}\right)^{p}}{T^{z}}\right|=\frac{Q^{\prime}}{\mathrm{R} T}+C
$$

where $t$ is the incubation time; $T$ is the temperature; $\mathrm{R}$ is the gas constant; $\Delta G_{m}$ is the available driving force for nucleation, calculated as a function of the activity of carbon in ferrite and austenite; and $C, p$, and $z$ are constants. Appropriated values for $C, p$, and $z$ can be found in Reference 26. According to this calculation, the incubation time for bainite at $250{ }^{\circ} \mathrm{C}$ is 1330 seconds, which explains the absence of bainite in the specimens partitioned at this temperature $\left(250^{\circ} \mathrm{C}\right.$ is a temperature below $M_{s}$, but bainite has been shown to form isothermally at temperatures below $M_{S}^{[28]}$ ). On the other hand, the calculated incubation time for bainite at $350{ }^{\circ} \mathrm{C}$ is only 20 seconds. This nucleation time reasonably agrees with the observation of a significant nucleation and growth of bainite in the specimen partitioned for 1000 seconds; this is in comparison with the specimen partitioned for 100 seconds, in which bainite was not observed.

During partitioning at $350{ }^{\circ} \mathrm{C}$, the overall microstructure evolution has been similar for every quenching temperature used, as is observed for partitioning at $250{ }^{\circ} \mathrm{C}$. Therefore, this indicates that, although the austenite available for the partitioning step is slightly different for every quenching temperature, variations of approximately $50^{\circ} \mathrm{C}$ in the quenching temperature do not significantly affect the final microstructure.

\section{Additional Comments}

The application of Q\&P heat treatments with partial austenitization has led to a microstructure formed by a large amount of ferrite $(0.74)$, which limits the effectiveness of this process in producing a novel microstructure.

The microstructures after these heat treatments have also shown martensite, retained austenite, and, in some cases, bainite. Carbide precipitation has been observed after partitioning for 1000 seconds at $250{ }^{\circ} \mathrm{C}$ and for 10 seconds at $350{ }^{\circ} \mathrm{C}$. In general, the degree to which these processes overlap with the carbon partitioning from the martensite to the austenite, the key to the Q\&P process, is considerable.

For the reasons stated earlier, the application of Q\&P heat treatments to typical TRIP chemistries seems difficult, because these chemical compositions are optimized for the promotion of bainite formation. This bainite, in TRIP steels, is formed by an isothermal treatment at a relatively high temperature; it is understandable, then, that the formation of epitaxial ferrite does not overly affect the resulting microstructure. However, in the case of the Q\&P process, the material is first cooled to a temperature below the martensitic start temperature. Therefore, in this case, the formation of epitaxial ferrite takes place in a higher temperature range, which leads to a higher presence of this phase and a significant effect on the final microstructure.

\section{CONCLUSIONS}

The Q\&P process has been studied in a low-carbon steel containing $1.1 \mathrm{wt}$ pct aluminum. The main results are presented in the following points.

1. Epitaxial ferrite forms during the first cooling of the specimens, at a cooling rate of $100{ }^{\circ} \mathrm{C} / \mathrm{s}$. The epitaxial ferrite introduces carbon-content gradients in the remaining austenite before the formation of martensite, leading to higher carbon content in the areas closer to the borders of the austenite grains. Therefore, martensite is formed within the grain during the quenching step, leaving untransformed the austenite closer to the grain boundaries.

2. It is experimentally observed that partitioning at $250{ }^{\circ} \mathrm{C}$ does not lead to an efficient carbon enrichment of the austenite. This might be due to the slow partitioning kinetics and to the possibility of the formation of carbides.

3. The occurrence of carbide precipitation during the partitioning step at $350{ }^{\circ} \mathrm{C}$ starts to be observed on samples isothermally treated for 10 seconds, but the kinetics of carbon partitioning is a dominant process at 100 seconds of partitioning time, leading to a considerable increase in the austenite volume fraction, to levels of approximately 0.08 .

4. At 1000 seconds of partitioning at $350{ }^{\circ} \mathrm{C}$, the decomposition of the austenite to upper bainite leads not only to an obvious increase in the carbon content of the austenite but also to a decrease in the volume fraction, to values approximately 0.03 .

5. The microstructure evolution during the partitioning step has been observed to be independent of the quenching temperature used, indicating that, although the austenite available for the partitioning step is slightly different for every quenching temperature, variations of approximately $50^{\circ} \mathrm{C}$ in the quenching temperature do not significantly affect the final microstructure in the cases analyzed in this study.

\section{ACKNOWLEDGMENTS}

The authors thank Dr. Carlos García de Andrés for providing the dilatometry facilities at the National Centre for Metallurgical Research (CENIM-CSIC) in Madrid, Spain, and acknowledge Mr. Orlando GarciaLeon and Dr. Roumen Petrov for their assistance and for the provision of the EBSD facilities at the University of Ghent, Belgium. The authors also thank Drs. Dave Hanlon and Theo Kop (Corus RD\&T, IJmuiden, The Netherlands) for fruitful discussions, and acknowledge the support Corus RD\&T provided for this project. 


\section{OPEN ACCESS}

This article is distributed under the terms of the Creative Commons Attribution Noncommercial License which permits any noncommercial use, distribution, and reproduction in any medium, provided the original author(s) and source are credited.

\section{REFERENCES}

1. J.G. Speer, A.M. Streicher, D.K. Matlock, F.C. Rizzo, and G. Krauss: in Austenite Formation and Decomposition, E.B. Damm and M. Merwin, eds., TMS/ISS, Warrendale, PA, 2003, pp. 505-22.

2. J.G. Speer, F.C. Rizzo, D.K. Matlock, and D.V. Edmonds: Mater. Res., 2005, vol. 8, pp. 417-23.

3. J.G. Speer, D.V. Edmonds, F.C. Rizzo, and D.K. Matlock: Curr. Opin. Solid State Mater. Sci., 2004, vol. 8, pp. 219-37.

4. D.V. Edmonds, K. He, F.C. Rizzo, A.M.S. Clarke, D.K. Matlock, and J.G. Speer: 1st Int. Conf. Super High Strength Steels, Associazione Italiana Di Metallurgica, Rome, Italy, 2005, pp. 1-20.

5. D.K. Matlock, V.E. Bräutigam, and J.G. Speer: Mater. Sci. Forum, 2003, vols. 426-432, pp. 1089-94.

6. D.V. Edmonds, K. He, M.K. Miller, F.C. Rizzo, A. Clarke, D.K. Matlock, and J.G. Speer: Mater. Sci. Forum, 2007, vols. 539-543, pp. 4819-25.

7. A.K. De, J.G. Speer, and D.K. Matlock: Adv. Mater. Processes, 2003 , pp. $27-30$

8. L. Zhao, N.H. van Dijk, E. Brück, J. Sietsma, and S. van der Zwaag: Mater. Sci. Eng., 2001, vol. 313A, pp. 145-52.

9. R.W. Cahn and P. Haasen: Physical Metallurgy, 3rd ed., Elsevier, Amsterdam, 1983, pp. 2558-60.

10. R.M. Bozorth: Ferromagnetism, D. Van Nostrad Company, Inc., New York, NY, 1961, pp. 367-68.
11. F.C. Schwerer, C.E. Spangler, and J.F. Delly, Jr.: Acta Metall., 1978, vol. 26, pp. 579-89.

12. B.D. Cullity: Elements of X-Ray Diffraction, Addison-Wesley, Reading, MA, 1978, pp. 359-67.

13. N.H. van Dijk, A.M. Butt, L. Zhao, J. Sietsma, S.E. Offerman, J.P. Wright, and S. van der Zwaag: Acta Mater., 2005, vol. 53, pp. 5439-47.

14. M.J. Santofimia, L. Zhao, R. Petrov, and J. Sietsma: Mater. Charact., 2008, doi:10.1016/j.matchar.2008.04.004.

15. B.M. Bronfin, M.I. Gol'dshteyn, A.A. Yemel'yanov, and A.Z. Shifman: Phys. Met. Metall., 1985, vol. 59, pp. 129-36.

16. S. Zaefferer, J. Ohlert, and W. Bleck: Acta Mater., 2004, vol. 53, pp. 2765-78.

17. G. Ghosh and G.B. Olson: Metall. Mater. Trans. A, 2001, vol. 32A, pp. 455-66.

18. D.P. Koistinen and R.E. Marburger: Acta Metall., 1959, vol. 7, pp. 59-60.

19. M.J. Santofimia, L. Zhao, and J. Sietsma: Proc. 2nd Int. Conf. Simulation and Modelling of Metallurgical Processes in Steelmaking, Graz, Austria, Andreas Ludwig, ed., ASMET, The Austrian Society for Metallurgy and Materials, 2007, pp. 368-73.

20. J.G. Speer, D.K. Matlock, B.C. De Cooman, and J.G. Schroth: Acta Mater., 2003, vol. 51, pp. 2611-22.

21. J.G. Speer, D.K. Matlock, B.C. De Cooman, and J.G. Schroth: Scripta Mater., 2005, vol. 52, pp. 83-85.

22. H.K.D.H. Bhadeshia and J.W. Christian: Metall. Trans. A, 1990, vol. 21A, pp. 767-97.

23. S.B. Singh and H.K.D.H. Bhadeshia: Mater. Sci. Eng., 1996, vol. 12A, pp. 610-12.

24. H.K.D.H. Bhadeshia: Met. Sci., 1981, vol. 15, pp. 178-80.

25. H.K.D.H. Bhadeshia: Bainite in Steels, The Institute of Materials, London, 2001, pp. 132-34.

26. H.K.D.H. Bhadeshia: Met. Sci., 1982, vol. 16, pp. 159-65.

27. K.C. Russell: Acta Metall., 1969, vol. 17, pp. 1123-31.

28. S.M.C. van Bohemem, M.J. Santofimia, and J. Sietsma: Scripta Mater., 2008, vol. 58, pp. 488-91. 